\title{
Effect of intraoperative iv dexmedetomidine on emergence agitation after sevoflurane anaesthesia in children undergoing tonsillectomy with or without adenoidectomy
}

\author{
Veena Mathur ${ }^{1}$, Pooran Chand Trivedi ${ }^{2}$, Deepak Kumar Garg ${ }^{3, *}$, Arvind Khare ${ }^{4}$, Surendra Sethi ${ }^{5}$ \\ ${ }^{1,4}$ Professor, ${ }^{2}$ Junior Resident, ${ }^{3,5}$ Assistant Professor, Dept. of Anaesthesiology, Raj University, Ajmer, Rajasthan, India
}

*Corresponding Author: Deepak Kumar Garg

Email: drdeepakgarg04@gmail.com

Received: $18^{\text {th }}$ May, 2018

Accepted: $23^{\text {rd }}$ June, 2018

\begin{abstract}
Introduction: Sevoflurane, a popular inhalational anaesthetic agent for paediatric anaesthesia is associated with high incidence of emergence agitation (up to 80\%). This study aims to evaluate the effects of intraoperative dexmedetomidine on incidence and severity of emergence agitation (EA) in children after tonsillectomy with or without adenoidectomy under sevoflurane anaesthesia.

Materials and Methods: This prospective, randomized double blind study included 70 patients aged 2-10 years with ASA physical status I and II who were randomly allocated into two groups. Group D $(n=35)$ received intravenous dexmedetomidine $0.3 \mu \mathrm{g} / \mathrm{kg}$ and Group $\mathrm{C}(\mathrm{n}=35)$ received normal saline, both given post intubation over $10 \mathrm{~min}$. After extubation, emergence agitation (EA) was assessed using the Pediatric Anesthesia Emergence Delirium (PAED) score, the Children's Hospital of Eastern Ontario Pain Scale (CHEOPS) for evaluating postoperative pain and modified Aldrete score for PACU discharge time were noted.

Results: Demographic profile was comparable between two groups. Incidence of emergence agitation was significantly less in Group D than Group C (20\% vs $42.86 \%$ ). Postoperative pain was significantly less in Group D in comparison of Group C (14.3\% vs $37.15 \%$ ). Emergence time, extubation time and PACU discharge time were significantly longer in Group D in comparison to Group C $(8.1 \pm 1.4$ vs $7.1 \pm 1.4 \mathrm{~min}, 9.06 \pm 1.59$ vs $8.06 \pm 1.39 \mathrm{~min}$ and $23.1 \pm 7.6$ vs $18.1 \pm 8.2$ min respectively $)$. No complications were observed between two groups except vomiting.

Conclusion: Dexmedetomidine $(0.3 \mu \mathrm{g} / \mathrm{kg})$ given intravenously just after intubation may be considered as an effective drug to reduce emergence agitation after sevoflurane anaesthesia in children undergoing tonsillectomy with or without adenoidectomy.
\end{abstract}

Keywords: Dexmedetomidine, Intraoperative, Emergence agitation, Sevoflurane, Tonsillectomy.

\section{Introduction}

Sevoflurane is a popular inhalational anaesthetic agent for paediatric anaesthesia due to it's nonpungent odour, low blood gas partition coefficient, rapid induction and emergence, weak airway irritation and better cardiovascular stability. ${ }^{1}$ Unfortunately it has been associated with high incidence (up to $80 \%$ ) of emergence agitation in children which is unrelated to duration of exposure and dose. ${ }^{2}$

Emergence agitation (EA) is defined as a postoperative negative behaviour characterized by combative movements, restlessness, thrashing, delirium and inconsolable crying. It can lead to injury to the children themselves or damage to surgical site with increased bleeding, disturbing the recovery environment causing stress to caregivers and parents and also associated with increased health care cost. ${ }^{3}$ Precise etiology of postoperative emergence agitation is unknown till now, however, many inciting factors related to patient, anaesthesia and surgery have been included such as preschool age, pain, anxiety, ENT surgeries, inhalational anaesthetics, rapid emergence, genetic predisposition. ${ }^{4}$

Various drugs including fentanyl, midazolam, ketamine and clonidine have been tried to prevent /treat emergence agitation with various results. ${ }^{5-8}$
Dexmedetomidine, a highly selective $\alpha_{2}$ adrenergic receptor agonist having sedative, anxiolytic and analgesic properties with stable hemodynamic without significant respiratory depressant effect has recently been used perioperatively to reduce postoperative emergence agitation (EA) and smoothen the recovery with unclear evidence, especially under sevoflurane anaesthesia. ${ }^{9,10}$

Therefore, we conducted a randomized prospective double blind placebo controlled study to test the hypothesis that single dose dexmedetomidine $0.3 \mu \mathrm{g} / \mathrm{kg}$ administered intravenously after endotracheal intubation would decrease the incidence and severity of emergence agitation as well as effect on postoperative recovery profile following sevoflurane based general anaesthesia in children undergoing tonsillectomy with or without adenoidectomy.

\section{Materials and Methods}

After obtaining approval from institutional ethical committee and written informed consent from parents, this prospective randomized study was conducted on a total of 70 paediatric patients aged 2 to 10 years with American Society of Anesthesiologists (ASA) physical status I and II, posted for tonsillectomy with or without adenoidectomy under general anaesthesia. All the 
patients were randomly allocated into two groups using computer generated table of random numbers. Group D $(\mathrm{n}=35)$; Dexmedetomidine Group and Group C ( $\mathrm{n}=$ 35); Saline Group.

Patients with age $<2$ years or $>10$ years, ASA grade III and above, allergic to dexmedetomidine or any other study drug, psychiatric illness, neurological illness, patient with reactive airway, parental refusal to take part in study were excluded from the study. The anaesthesiologist was not blinded to the procedure but the patient and assessor of Pediatric Anesthesia Emergence Delirium (PAED) score were blinded to group allocation.

All the patients were kept nil per oral for 6 hours for solid and 2 hours for clear liquid and received injection glycopyrrolate $5 \mu \mathrm{g} / \mathrm{kg}$ intravenous given 30 min before shifting the patient to the operating room. Upon arrival in the operating room, standard monitoring including electrocardiography (ECG), noninvasive blood pressure (NIBP) and pulse oximeter $\left(\mathrm{SpO}_{2}\right)$, were applied to all patients and baseline parameters were recorded. All patients received inj. tramadol $2 \mathrm{mg} / \mathrm{kg}$ intravenously as preemptive analgesic followed by induction with sevoflurane $8 \%$ in oxygen @ 6 liter/min, followed by IPPV. Endotracheal intubation was done using atracurium $0.5 \mathrm{mg} / \mathrm{kg}$ intravenously followed by confirmation of endotracheal tube by chest auscultation and capnography.

Patients in Group D $(\mathrm{n}=35)$ received Inj. dexmedetomidine intravenously over 10 minutes after endotracheal intubation at a dose of $0.3 \mathrm{mcg} / \mathrm{kg}$ of body weight diluted with normal saline to $10 \mathrm{ml}$ and Group C $(\mathrm{n}=35)$ received $10 \mathrm{ml}$ normal saline over 10 minutes.

Maintenance of anaesthesia was done using sevoflurane maintaining haemodynamic stability + oxygen \& nitrous oxide (50:50) with controlled mechanical ventilation. Intraoperative vitals (HR, NIBP, and SpO2) were monitored and recorded at just after intubation, 5, 10, 20, 30 and 45 minutes post intubation. Extubation was done in left lateral position after adequate reversal and return of gag reflex.

After extubation, at $0,5,15$, and $30 \mathrm{~min}$, emergence agitation (EA) was assessed using the Pediatric Anesthesia Emergence Delirium (PAED) score(11), the Children's Hospital of Eastern Ontario Pain Scale(CHEOPS) for evaluating postoperative pain(12) and modified Aldrete score for PACU discharge time (13) were noted by the same blinded anaesthesiologist. (Table 1).

Duration of surgery (time from mouth opening till completion of the surgery), duration of anaesthesia (time from mask induction to discontinuation of inhaled anaesthetic), emergence time (from discontinuation of sevoflurane to the first response to a simple verbal command), extubation time (from the discontinuation of sevoflurane to the removal of endotracheal tube) and PACU discharge time (from arrival to the PACU until discharge) were noted. Incidence of adverse event, if any, was also noted. Inj. Fentanyl at a dose of $0.5 \mathrm{mcg} / \mathrm{kg}$ intravenously was used as rescue analgesic and rescue medicine for EA if PAED score more than 10 and if required repeated after 10 minutes.

Table 1: PAED (Pediatric anesthesia emergence delirium) score

\begin{tabular}{|l|c|c|c|c|c|}
\hline \multicolumn{1}{|c|}{ Behaviour } & Not at all & Just a little & Quite a bit & Very much & Extremely \\
\hline Makes eye contact with caregiver & 4 & 3 & 2 & 1 & 0 \\
\hline Actions are purposeful & 4 & 3 & 2 & 1 & 0 \\
\hline Aware of surroundings & 4 & 3 & 2 & 1 & 0 \\
\hline Restless & 0 & 1 & 2 & 3 & 4 \\
\hline Inconsolable & 0 & 1 & 2 & 3 & 4 \\
\hline
\end{tabular}

*Range $0-20 ;$ Score $\geq 10$ showed presence of agitation.

\section{Statistical Analysis}

Sample size was calculated to be 35 patients in each group keeping a power of $0.8, \alpha$ error of 0.05 and allowing for study error and attrition. Variables were analyzed statistically and expressed as mean \pm standard deviation. Categorical data were compared using Chisquare test or Fisher exact test as appropriate. Quantitative parametric data were analyzed using unpaired student $t$-test while non-parametric data were analyzed using Mann-Whitney test. P value $<0.05$ was considered statistically significant.

\section{Results}

Demographic profile was comparable between two groups in terms of age, sex, weight, ASA physical status (Table 2). Duration of surgery, duration of anaesthesia and intraoperative haemodynamics were also comparable.

Prevalence of emergence agitation was lesser in patients of group D in comparison to group $\mathrm{C}$ just after extubation, at 5 and $15 \mathrm{~min}$ and was statistically significant $(p<0.05)$. Prevalence of patients exhibiting EA was highest just after extubation and progressively decreased over time in both groups. Total 7 (20\%) patients in group D exhibited EA compared to $15(42.86 \%)$ in group C (Table 3$)$.

Number of patients with pain(CHEOPS Score $>4)$ were less in group $\mathrm{D}$ in comparison to group $\mathrm{C}(5 \mathrm{v} / \mathrm{s} 13$, $3 \mathrm{v} / \mathrm{s} 10$ and $0 \mathrm{v} / \mathrm{s} 4)$ just after extubation, at 5 and $15 \mathrm{~min}$ respectively and that was statistically significant( $\mathrm{p}$ $<0.05$ ). There was no patient with pain at $30 \mathrm{~min}$ in both the groups. 13 patients in group $\mathrm{C}$ required rescue analgesia compared to 5 in group D $(\mathrm{p}<0.05)$ (Table 4). 
The Modified Aldrete score was less in group D in comparison to group $\mathrm{C}$ just after extubation, at 5 and $15 \mathrm{~min}$ and it was statistically significant $(\mathrm{p}<0.05)$, however, The Score at $30 \mathrm{~min}$. was comparable ( $>>0.05)$ (Table 5). The PACU discharge time was also higher in group D $(23.1 \pm 7.6 \mathrm{~min})$ in comparison to group $\mathrm{C}(18.1 \pm 8.2 \mathrm{~min})$ and was found to be statistically significant $(\mathrm{p}<0.05)$.

The mean emergence time was higher in group D $(8.1 \pm 1.4 \mathrm{~min})$ in comparison to group $\mathrm{C}(7.1 \pm 1.4$ min) and was statistically significant $(\mathrm{p}<0.05)$. The mean extubation time was longer in group D (9.06 \pm $1.59 \mathrm{~min})$ in comparison to group $\mathrm{C}(8.06 \pm 1.39 \mathrm{~min})$ and was statistically significant $(\mathrm{p}<0.05)$.

Incidence of vomiting was comparable between Group C and group D (14.3\% v/s $8.6 \%$ respectively); $(\mathrm{p}>0.05)$. Other adverse effects like laryngospasm, bronchospasm were not seen in any patient.

Table 2: Demographic profile in two groups

\begin{tabular}{|l|c|c|c|}
\hline & $\begin{array}{c}\text { Group C } \\
(\mathbf{n}=35)\end{array}$ & $\begin{array}{c}\text { Group D } \\
(\mathbf{n}=35)\end{array}$ & P Value \\
\hline Age (Yr) & $8.3 \pm 1.7$ & $8.5 \pm 1.7$ & 0.72 \\
\hline Sex (M/F) \% & $60 / 40$ & $57.1 / 42.9$ & 0.81 \\
\hline Weight (Kg) & $25.8 \pm 6.3$ & $26.6 \pm 6.7$ & 0.62 \\
\hline ASA physical status (I /II) \% & $57.1 / 42.9$ & $54.3 / 45.7$ & 0.81 \\
\hline
\end{tabular}

Values are expressed as Mean \pm Standard deviation and percentage

Table 3: Emergence agitation in two groups

\begin{tabular}{|l|c|c|c|c|c|}
\hline \multicolumn{1}{|c|}{ Time } & $\begin{array}{c}\text { Group C } \\
(\mathbf{n = 3 5})\end{array}$ & $\begin{array}{c}\text { Percentage } \\
(\mathbf{\%})\end{array}$ & $\begin{array}{c}\text { Group D } \\
(\mathbf{n = 3 5})\end{array}$ & $\begin{array}{c}\text { Percentage } \\
(\boldsymbol{\%})\end{array}$ & P value \\
\hline Just after extubation & 15 & 42.9 & 7 & 20 & 0.04 \\
\hline 5 min. & 12 & 34.3 & 5 & 14.3 & 0.05 \\
\hline 15 min. & 6 & 17.1 & 0 & 0 & 0.01 \\
\hline 30 min. & 0 & 0 & 0 & 0 & - \\
\hline
\end{tabular}

Table 4: Pain (CHEOPS score $>4$ ) in two groups

\begin{tabular}{|l|c|c|c|c|c|}
\hline \multicolumn{1}{|c|}{ Time } & $\begin{array}{c}\text { Group } \\
\mathbf{C ( n = 3 5 )}\end{array}$ & $\begin{array}{c}\text { Percentage } \\
(\mathbf{\%})\end{array}$ & $\begin{array}{c}\text { Group } \\
\mathbf{D ( n = 3 5 )}\end{array}$ & $\begin{array}{c}\text { Percentage } \\
(\mathbf{\%})\end{array}$ & P value \\
\hline Just after extubation & 13 & 37.1 & 5 & 14.3 & 0.03 \\
\hline 5 min. & 10 & 28.6 & 3 & 8.6 & 0.03 \\
\hline 15 min. & 4 & 11.4 & 0 & 0 & 0.04 \\
\hline 30 min. & 0 & 0 & 0 & 0 & - \\
\hline
\end{tabular}

Table 5: Modified Aldrete score in two groups

\begin{tabular}{|l|c|c|c|}
\hline \multicolumn{1}{|c|}{ Time } & \multicolumn{3}{|c|}{ Modified Aldrete Score } \\
\cline { 2 - 4 } & $\begin{array}{c}\text { Group C } \\
(\mathbf{n = 3 5})\end{array}$ & $\begin{array}{c}\text { Group D } \\
(\mathbf{n = 3 5})\end{array}$ & P Value \\
\hline Just after extubation & $6.5 \pm 1.0$ & $5.9 \pm 0.8$ & 0.01 \\
\hline 5 min. & $7.8 \pm 0.7$ & $7.3 \pm 0.5$ & 0.01 \\
\hline 15 min. & $8.8 \pm 0.6$ & $8.4 \pm 0.6$ & 0.01 \\
\hline 30 min. & $9.4 \pm 0.5$ & $9.5 \pm 0.5$ & 0.61 \\
\hline
\end{tabular}

\section{Discussion}

Sevoflurane is widely used inhalational anaesthetic for paediatric anaesthesia however it is associated with high incidence (up to $80 \%$ ) of emergence agitation (EA) in children which may be due to rapid awakening and pain. However various studies have found protective role of propofol against EA compared to sevoflurane despite rapid emergence which contradicts fact, ${ }^{14,15}$ although Lee et $\mathrm{al}^{16} \mathrm{did}$ not find any significant effect on EA compare to sevoflurane.

Drugs such as dexmedetomidine, an $\alpha_{2-}$ adrenoceptor agonist may improve EA after sevoflurane anaesthesia. It has got sedative, analgesic and anxiolytic properties with few adverse effects which make it a suitable drug to be used for this purpose. The dose of $0.3 \mu \mathrm{g} / \mathrm{kg}$ use in our study was based on previous studies. Manal $\mathrm{M}$ concluded that dexmedetomidine $0.3 \mu \mathrm{g} / \mathrm{kg}$ administered postintubation reduced the EA after sevoflurane anaesthesia without delayed recovery or hemodynamic instability. ${ }^{17}$

The various demographic parameters including mean age, mean weight, sex and ASA physical status were comparable between two groups $(p>0.05)$. The mean age was $8.5 \pm 1.7$ years and $8.3 \pm 1.7$ years in 
group D and group $\mathrm{C}$ respectively ( $\mathrm{p}>0.05$ ). The mean weight was $26.6 \pm 6.7 \mathrm{~kg}$ and $25.8 \pm 6.3 \mathrm{~kg}$ in group $\mathrm{D}$ and group $\mathrm{C}$ respectively $(\mathrm{p}>0.05)$. The number of male/female were $21 / 14$ and $20 / 15$ in group $C$ and in group D respectively and were comparable. The number of patients with ASA I / II were 20/15 and $19 / 16$ in group C and group D respectively and were comparable (Table 3 ). In various previous studies the incidence of EA was found to be maximum in paediatric age group undergoing ear, nose and throat surgeries (ENT) especially under sevoflurane anaesthesia, thus we investigated dexmedetomidine in similar patients. The high incidence of EA in ENT surgeries is postulated to be due to a sense of suffocation in surgeries related to airways. ${ }^{18}$

In our study, the severity of EA was assessed using Paediatric Anaesthesia Emergence Delirium (PAED) Score. The mean PAED score was significantly low $(p<0.05)$ in group $D$ in comparison to group $C$ just after extubation, at 5, 15, and 30minutes. There was also a gradual decrease in score over the time and showed incidence of EA was in peak in just after extubation to first $15 \mathrm{~min}$. Total $7(20 \%)$ patients in group D exhibited EA compared to 15 (42.9\%) in group C.

Dexmedetomidine may be effective drug in reducing emergence agitation because of its sedative, anxiolytic and analgesic properties that is due to its action in locus coeruleus in the brain stem by stimulating $\alpha_{2}$-adrenoceptor. ${ }^{9}$ Dexmedetomidine also produces it's analgesic action via presynaptic receptors by inducing hyperpolarization and inhibiting pain signals. Dexmedetomidine also activates endogenous sleep pathway thus producing stage 2 non rapid eye movement (NREM) sleep resulting in conscious sedation without respiratory depression. ${ }^{19}$

Ibacache et $\mathrm{al}^{20}$ in their study found that post induction dexmedetomidine reduces post sevoflurane EA in children compared to placebo $(10 \% \mathrm{v} / \mathrm{s} 37 \%)$ that was comparable to our study. Gulen Guler et $\mathrm{al}^{10}$ in their study observed that dexmedetomidine reduces incidence and severity of EA after sevoflurane anaesthesia in children undergoing adenotonsillectomy. Similarly $\mathrm{C}$ Zhang et $\mathrm{al}^{8}$ in their meta-analysis concluded that dexmedetomidine reduces the incidence of EA, which support our study.

The severity of postoperative pain in PACU was assessed by Children's Hospital of Eastern Ontario Pain Scale (CHEOPS) that was less in group $\mathrm{D}$ in comparison to group $\mathrm{C}$ just after extubation and at $5 \mathrm{~min}$, and was statistically significant $(\mathrm{p}<0.05)$. The mean CHEOPS Score was comparable at $15 \mathrm{~min}$ in both groups $(\mathrm{p}>0.05)$. A significantly more number of patients required rescue analgesia in group $\mathrm{C}$ compared to group D (37.14\% vs $14.28 \%)$. Fentanyl $0.5 \mu \mathrm{g} / \mathrm{kg}$ was given as rescue analgesic when CHEOPS score was $>4$. Min $\mathrm{Zhu}$ et $\mathrm{al}^{21}$ in their meta-analysis found that dexmedetomidine decreased the incidence of pain in children undergoing sevoflurane anaesthesia. Sato $\mathrm{M}$ et $\mathrm{al}^{22}$ reported that dexmedetomidine $0.3 \mu \mathrm{g} / \mathrm{kg}$ postinduction reduced sevoflurane associated EA and post operative pain in pediatric ambulatory surgery without adverse events, thus supporting our study.

Fentanyl was not used as preventive analgesic because it is known to reduce EA which may interfere with the results associated with the use of dexmedetomidine and we wanted to investigate effect of dexmedetomidine only. Also it is associated with respiratory depression and nausea, vomiting. ${ }^{23}$

In our study many of the children had pain and agitation along with, which may explain pain as causative factor of EA but EA may not be related to pain alone as indicated in study by Manal $\mathrm{M}$ et $\mathrm{al}^{16}$ in which he found comparable pain score but decreased EA with dexmedetomidine compared to placebo. Similarly, Isik et $\mathrm{al}^{24}$ also reported $48 \%$ incidenc of EA in pediatric patients undergoing MRI.

PACU discharge time was found to be statistically significantly $(\mathrm{p}<0.05)$ prolonged in group $\mathrm{D}$ than group $\mathrm{C}(23.1 \pm 7.6 \mathrm{v} / \mathrm{s} 18.1 \pm 8.2 \mathrm{~min})$. This could be explained by sedative effect of dexmedetomidine but the children remained arousable with stable haemodynamics. Children were discharged from PACU to the ward when modified Aldrete score was $\geq 9$ without agitation and vomiting.

Baseline HR, SBP, DBP, MABP and $\mathrm{SpO}_{2}$ were comparable in both groups. These parameters were also comparable at various time intervals after intubation and extubation. All the values of MABP were less in group D in comparison of group C (however it was clinically acceptable), that could be due to hypotensive effect of dexmedetomidine in patients of group D. Though dexmedetomidine produces dose-dependent decrease in HR and BP, Manal $\mathrm{M}$ et $\mathrm{al}^{17}$ and Guler et $\mathrm{al}^{10}$ in their study found no perioperative adverse haemodynamic effects of a $0.3-0.5 \mu \mathrm{g} / \mathrm{kg}$ bolus dose which was comparable to our study. The low dose dexmedetomidine infused slowly over 10 minutes may have avoided adverse hemodynamic effects.

Duration of surgery and duration of anaesthesia were comparable in both the groups $(p>0.05)$ which preclude them to be a biasing factor, thus supporting our study. The mean emergence time was $8.1 \pm 1.4 \mathrm{~min}$ in group D and $7.1 \pm 1.4 \mathrm{~min}$ in group $\mathrm{C}$ that was statistically significant $(p<0.05)$. Similarly the mean extubation time was significantly prolonged in group D $(9.06 \pm 1.59 \mathrm{~min})$ in comparison to in group $\mathrm{C}$ $(8.06 \pm 1.39 \mathrm{~min})$. These may be due to excessive sedation due to dexmedetomidine and may also contribute to decreased EA. Zhang et $\mathrm{al}^{8}$ also found that extubation time and PACU discharge time were prolonged in dexmedetomidine group in comparison to placebo group and was statistically significant $(\mathrm{p}<0.05)$. In our study also results were comparable to this. Similarly, Gulen Guler et $\mathrm{al}^{10}$ also found that emergence time and extubation time were longer in dexmedetomidine group. 
The incidence of vomiting was comparable in both the groups $(p>0.05)$ and patients were managed with single intravenous dose of ondansetron $0.1 \mathrm{mg} / \mathrm{kg}$.

\section{Limitations of our Study}

1. Assessment of CHEOP score and PAED score is subjective and may vary with the level of understanding of anaesthesiologist.

2. It was a single centre study only.

3. The study was restricted to ENT department only. So further studies may be undertaken which include more generalized patient population for better and more accurate results.

\section{Conclusion}

We conclude that $0.3 \mu \mathrm{g} / \mathrm{kg}$ intravenous dexmedetomidine administered just after intubation significantly decreases incidence and severity of emergence agitation after sevoflurane based anaesthesia in children undergoing tonsillectomy with or without adenoidectomy, with decreased postoperative pain and smooth postoperative course without any adverse effect but at the cost of prolonged emergence time and extubation time with prolonged PACU discharge time.

\section{Conflict of Interest: None}

\section{References}

1. Lerman J, Davis PJ, Welborn LG. Induction, recovery, and safety characteristics of sevoflurane in children undergoing ambulatory surgery. A comparison with halothane. Anesthesiology. 1996;84(6):1332-1340.

2. Kuratani N, Oi Y. Greater incidence of emergence agitation in children after sevoflurane anesthesia as compared with halothane: A meta-analysis of randomized controlled trials. Anesthesiology. 2008;109:225-232.

3. Silva LM, Braz LG, Módolo NS. Emergence agitation in pediatric anesthesia: Current features. J Pediatr (Rio J). 2008;84:107-113.

4. Aouad M.T. and Nasr V.G.: Emergence agitation in children: An update. Curr Opin Anaesthesiol. 2005; 18:614-619.

5. Cohen IT, Finkel JC, Hannallah RS. The effect of fentanyl on the emergence characteristics after desflurane or sevoflurane anesthesia in children. Anesth. Analg. 2002;94:1178-1181.

6. Tazeroualti N, De GF, De HS. Oral clonidine vs midazolam in the prevention of sevoflurane-induced agitation in children. A prospective, randomized, controlled trial. Br J Anaesth. 2007;98:667-671.

7. Gupta N, Rath GP, Prabhakar H. Effect of intraoperative dexmedetomidine on postoperative recovery profile of children undergoing surgery for spinal dysraphism. $J$ Neurosurg Anesthesiol. 2013;25:271-278.

8. Chengliang Zhang, Jiajia Hu, Liu X. Effects of intravenous dexmedetomidine on emergence agitation in children under sevoflurane anesthesia: a meta-analysis of randomized controlled trials. PLoS One.

2014;9(6):e99718. doi:10.1371/journal.pone.0099718.

9. Hall JE, Uhrich TD, Barney JA. Sedative, amnestic, and analgesic properties of small dose dexmedetomidine infusions. Anesth Analg 2000; 90:699-705.
10. Guler G, Akin A, Tosun Z. Single-dose dexmedetomidine reduces agitation and provides smooth extubation after pediatric adenotonsillectomy. Paediatr Anaesth. 2005;15(9):762-766.

11. Sikich N., Lerman J. Development and psycho-metric evaluation of the pediatric anesthesia emergence delirium scale. Anesthesiology. 2004 May;100(5):1138-45.

12. S Suraseranivongse, U Santawat, K Kraiprasit. Cross-validation of a composite pain scale for preschool children within 24 hours of surgery. $\mathrm{Br} \mathrm{J}$ Anaesth. 2001;87:400-5

13. Aldrete JA. The post-anesthesia recovery score revisited. J Clin Anesth. 1995;7:89.

14. Cohen IT, Finkel JC, Hannallah RS. Rapid emergence does not explain agitation following sevoflurane anaesthesia in infants and children: A comparison with propofol. Paediatr Anaesth. 2003;13:63-67.

15. Ali MA, Abdellatif A. Prevention of sevoflurane related emergence agitation in children undergoing adenotonsillectomy. A comparison of dexmedetomidine and propofol. Saudi J Anaesth. 2013;7(3):296-300.

16. Lee CJ, Lee SE, Oh MK. The effect of propofol on emergence agitation in children receiving sevoflurane for adenotonsillectomy. Korean J Anesthesiol. 2010;59(2):75-81.

17. Manal M, El-Gohary, Sherry N. Dexmedetomidine for Emergence Agitation after Sevoflurane Anesthesia in Preschool Children Undergoing Day Case Surgery: Comparative Dose-Ranging Study. Med J Cairo Univ. 2011;79(2):17-23.

18. Guler G, Akin A, Tosun Z. Single-dose dexmedetomidine reduces agitation and provides smooth extubation after pediatric adenotonsillectomy. Paediatr Anaesth. 2005; 15:762-766.

19. Phan H, Nahata MC. Clinical uses of dexmedetomidine in pediatric patients. Paediatr Drugs. 2008;10:49-69.

20. Ibacache ME, Munoz HR, Brandes V. Single-dose dexmedetomidine reduces agitation after sevoflurane anesthesia in children. Anesth Analg. 2004;98:60-63.

21. Min Zhu Wang H, Zhu A. Meta-Analysis of Dexmedetomidine on Emergence Agitation and Recovery Profiles in Children after Sevoflurane Anesthesia: Different Administration and Different Dosage. PLoS One. 2015;10(4): $\mathrm{e} 0123728$. https://doi.doi:10.1371/journal.pone.0123728.

22. Sato M, Shirakami G, Tazuke-Nishimura M. Effect of single-dose dexmedetomidine on emergence agitation and recovery profiles after sevoflurane anesthesia in pediatric ambulatory surgery. J Anesth. 2010;24:675-682.

23. Kim MS, Moon BE, Kim H. Comparison of propofol and fentanyl administered at the end of anaesthesia for prevention of emergence agitation after sevoflurane anaesthesia in children. Br J Anaesth. 2013;110(2):274280.

24. Isik B, Arslan M, Tunga AD. Dexmedetomidine decreases emergence agitation in pediatric patients after sevoflurane anesthesia without surgery. Paediatr Anaesth. 2006;16:748-753.

How to cite this article: Mathur V, Trivedi P C, Garg D K, Khare A, Sethi S. Effect of intraoperative iv dexmedetomidine on emergence agitation after sevoflurane anaesthesia in children undergoing tonsillectomy with or without adenoidectomy. Indian $\mathbf{J}$ Clin Anaesth. 2018;5(4):496-500. 